\title{
Pengaruh kualitas website Kandaga terhadap kepuasan pengguna Perpustakaan Pusat Universitas Padjadjaran
}

\author{
Eko Retno Wulandari', Edwin Rizal2 ${ }^{2}$ Elnovani Lusiana ${ }^{3}$ \\ ${ }^{1}$ Perpustakaan FMIPA, Universitas Padjadjaran \\ 2,3Program Studi Perpustakaan dan Sains Informasi, Universitas Padjadjaran \\ Jl. Raya Bandung-Sumedang Km. 21, Jatinangor, Sumedang, Jawa Barat, 45363

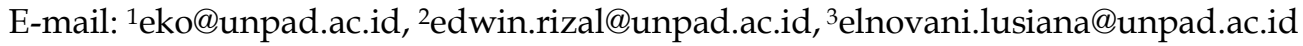

Received: August 2020; Accepted: May 2021; Published: June 2021

\begin{abstract}
Library websites in higher education institutions help increase competitiveness and reinforce institutions, information media, and library promotion. This study aimed to determine the effect of the quality of the Kandaga website partially and simultaneously on user satisfaction at the Padjadjaran University Central Library. This study used an explanatory quantitative approach by distributing questionnaires to 373 people. The analysis of research data used path analysis. Based on the research results, variables of usability quality, service interaction quality, interface quality, and digital library service quality partially had a significant effect on user satisfaction of the Padjadjaran University Central Library. The quality of the Kandaga website had a significant simultaneous effect on user satisfaction of the Central Library of Padjadjaran University by $87.4 \%$. The quality of the digital library services had the most significant influence on user satisfaction, namely 52.6\%. The Central Library o Padjadjaan University needed to prioritize digital library service quality improvements because this variable significantly influenced user satisfaction. The quality of the Kandaga website partially and simultaneously had a significant effect on user satisfaction of the Central Library. Information quality had no significant effect on user satisfaction of the Central Library of Padjadjaran University. Kandaga's information quality variable had the highest value. The study concludes that users of the Kandaga website believe that the quality of information on the Kandaga website currently has met user needs, has a good reputation, is trustworthy, relevant, detailed, and easy to understand.
\end{abstract}

Keywords: Website quality; User satisfaction; Kandaga; Padjadjaran University Library

\begin{abstract}
Abstrak
Website perpustakaan di perguruan tinggi bermanfaat untuk meningkatkan daya saing dan basis penguatan institusi, media informasi, dan promosi perpustakaan. Penelitian ini bertujuan untuk mengetahui pengaruh kualitas website Kandaga secara parsial dan simultan terhadap kepuasan pengguna Perpustakaan Pusat Universitas Padjadjaran. Pendekatan yang digunakan adalah pendekatan kuantitatif bersifat eksplanatori dengan kuesioner yang disampaikan kepada 373 orang. Analisis data penelitian menggunakan analisis jalur (path analysis). Berdasarkan hasil penelitian diperoleh bahwa variabel kualitas kegunaan, kualitas interaksi pelayanan, kualitas antarmuka, dan kualitas pelayanan perpustakaan digital secara parsial berpengaruh signifikan terhadap kepuasan pengguna Perpustakaan Pusat Universitas Padjadjaran. Kualitas website Kandaga secara simultan berpengaruh signifikan terhadap kepuasan pengguna Perpustakaan Pusat Universitas Padjadjaran sebesar 87,4\%. Kualitas pelayanan perpustakaan digital berpengaruh paling besar terhadap kepuasan pengguna yaitu sebesar $52,6 \%$. Prioritas peningkatan dan perbaikan kualitas pelayanan perpustakaan digital Kandaga perlu dilakukan Perpustakaan Pusat Universitas Padjadjaran karena variabel ini yang memiliki pengaruh paling besar terhadap kepuasan pengguna. Kualitas website Kandaga secara parsial dan simultan berpengaruh signifikan terhadap kepuasan pengguna Perpustakaan Pusat Universitas Padjadjaran. Kualitas informasi tidak berpengaruh signifikan terhadap kepuasan pengguna Perpustakaan Pusat Universitas Padjadjaran. Nilai variabel kualitas informasi Kandaga memiliki nilai paling tinggi dibandingkan variabel lain. Simpulan penelitian ini ialah pengguna website percaya bahwa kualitas informasi website Kandaga saat ini telah dapat memenuhi kebutuhan pengguna, mempunyai reputasi yang baik, dapat dipercaya, relevan, detail, dan mudah dimengerti.
\end{abstract}

Kata Kunci: Kualitas website; Kepuasan pengguna; Kandaga; Perpustakaan Universitas Padjadjaran 


\section{PENDAHULUAN}

Internet memberikan kemudahan pada masyarakat dalam memenuhi kebutuhan informasi dan aktualisasi diri. Salah satunya penggunaan internet di perpustakaan. Untuk itu, perpustakaan perlu mentransformasikan pelayanan perpustakaan agar pemberian pelayanan efektif dan cepat. Perpustakaan dapat menggunakan internet sebagai sarana promosi citra perpustakaan, peningkatan sumber daya informasi yang tersedia secara efektif, menarik, mempertahankan loyalitas pengguna, peningkatan kepuasan pengguna, dan memfasilitasi organisasi sumber daya informasi secara tepat.

Perpustakaan menerapkan pelayanan perpustakaan berbasis internet agar perpustakaan tidak ditinggalkan pengguna. Semakin banyak perpustakaan yang berbagi informasi secara online, makin banyak pengguna perpustakaan menggunakan pelayanan perpustakaan. Saat ini, perpustakaan sudah memiliki sebuah media untuk mewadahi informasi yang dimilikinya, berupa website. Website adalah media baru yang dapat digunakan perpustakaan sebagai media promosi dan pemasaran dalam mengomunikasikan dan menawarkan apa yang dimiliki perpustakaan.

Website perpustakaan adalah pintu masuk pengguna mencari informasi di perpustakaan. Adapun website perpustakaan perguruan tinggi memiliki tujuan menyediakan akses dan mendukung kegiatan penelitian, pengajaran, dan pelayanan publik (Junaeti, \& Arwani, 2016). Teknologi informasi mendorong perpustakaan untuk melakukan perubahan pelayanan. Hal ini membantu masyarakat umum dapat mengakses sumber daya online termasuk katalog online melalui website.
Internet memberikan kemudahan pada masyarakat dalam memenuhi kebutuhan informasi dan aktualisasi diri. Salah satunya penggunaan internet di perpustakaan. Untuk itu, perpustakaan perlu mentransformasikan pelayanan perpustakaan agar pemberian pelayanan efektif dan cepat. Perpustakaan dapat menggunakan internet sebagai sarana promosi citra perpustakaan, peningkatan sumber daya informasi yang tersedia secara efektif, menarik, mempertahankan loyalitas pengguna, peningkatan kepuasan pengguna, dan memfasilitasi organisasi sumber daya informasi secara tepat.

Perpustakaan menerapkan pelayanan perpustakaan berbasis internet agar perpustakaan tidak ditinggalkan pengguna. Semakin banyak perpustakaan yang berbagi informasi secara online, makin banyak pengguna perpustakaan menggunakan pelayanan perpustakaan. Saat ini, perpustakaan sudah memiliki sebuah media untuk mewadahi informasi yang dimilikinya, berupa website. Website adalah media baru yang dapat digunakan perpustakaan sebagai media promosi dan pemasaran dalam mengomunikasikan dan menawarkan apa yang dimiliki perpustakaan.

Website perpustakaan adalah pintu masuk pengguna mencari informasi di perpustakaan. Adapun website perpustakaan perguruan tinggi memiliki tujuan menyediakan akses dan mendukung kegiatan penelitian, pengajaran, dan pelayanan publik (Junaeti, \& Arwani, 2016). Teknologi informasi mendorong perpustakaan untuk melakukan perubahan pelayanan. Hal ini membantu masyarakat umum dapat mengakses sumber daya online termasuk katalog online melalui website.

Berdasarkan Google Analytic (2019), 
Perpustakaan Pusat Universitas Padjadjaran memiliki tingkat penggunaan website dari bulan Oktober 2018 sampai Desember 2019 sejumlah 38.859 kali kunjungan. Wilayah yang banyak mengakses website Kandaga berasal dari Bandung yang diakses sebanyak 14.175 kali kunjungan. Adapun pengguna yang banyak mengakses menggunakan login https:// paus.unpad.ac.id/ sebanyak 5.478 orang.

Pengguna website Kandaga terdiri dari mahasiswa berjumlah 35.885 orang dan tenaga pendidik berjumlah 1.704 orang. Para pengguna telah memanfaatkan website Kandaga dengan mengunduh dokumen jurnal elektronik yang dihasilkan Universitas Padjadjaran dan jurnal elektronik yang dilanggan berjumlah kurang dari 2.000 unduhan. Sesuai data di atas, website Kandaga telah menyediakan sumber informasi elektronik untuk memenuhi kebutuhan sivitas akademika Universitas Padjadjaran.

Selain itu, data Google Analytic (2019) mencatat bahwa telah ada kenaikan kunjungan pengguna pada September, namun ada penurunan pengguna pada bulan berikutnya secara terus menerus. Website Kandaga mengalami kenaikan pada September karena bertepatan dengan penerimaan mahasiswa baru, kegiatan bimbingan pengguna, dan sosialisasi perpustakaan termasuk sosialisasi website Kandaga. Adapun sesuai pengamatan Google Scholar (2021), sebagian besar sitasi yang digunakan dalam penulisan artikel ilmiah tenaga pendidik Universitas Padjadjaran ialah menggunakan jurnal elektronik. Untuk itu, Perpustakaan Pusat Universitas Padjadjaran telah menyediakan jurnal online pada website Kandaga agar banyak dimanfaatkan tenaga pendidik.
Hal ini sesuai pernyataan Wulandari, Rizal, and Lusiana (2020) yang telah melakukan survei pada 120 mahasiswa generasi z Universitas Padjadjaran. Hasil survei menghasilkan data sejumlah 107 responden yang jarang mengakses e-book dan electronic journal dan 13 responden sering mengakses e-book dan electronic journal pada website Kandaga. Sebagian besar responden jarang mengakses e-book dan electronic journal pada website Kandaga. Padahal, sivitas akademika Universitas Padjadjaran dapat menggunakan e-book dan electronic journal untuk mendukung pembelajaran. Apalagi, mahasiswa menggunakan buku dan jurnal dalam setiap penyusunan laporan praktikum dan tugas meringkas jurnal. Untuk itu, Perpustakaan Pusat Universitas Padjadjaran harus bekerja keras mempromosikan website Kandaga pada sivitas akademika agar sumber informasi online dapat dimanfaatkan semua kalangan.

Website Kandaga sendiri telah membantu mahasiswa dan tenaga pendidik dalam mendapatkan sumber informasi yang cepat, akurat, dan beragam. Hal ini menandakan bahwa website perpustakaan perguruan tinggi sangat penting dirancang dan dilayankan kepada pengguna. Syaifullah and Soemantri (2016) mengatakan bahwa untuk melihat kualitas sebuah website dapat dilihat melalui teori WebQual. Website melalui teori WebQual dapat dianalisis melalui variabel kualitas kegunaan, kualitas interaksi layanan, dan kualitas informasi, pengukuran kualitas website yang menitikberatkan pada pengukuran kepuasan konsumen (user), dan persepsi pengguna berdasarkan Quality Function Deployment (QFD).

Selain itu, pengguna yang tertarik 
mengakses website dapat melihat dari antarmuka website, yakni halaman website untuk interaksi dengan pengguna saat pertama kali. Kualitas antarmuka merupakan hal penting pada sebuah website karena pengguna dapat berinteraksi pertama kali dengan melihat antarmuka website (Rochmawati, 2019). Sebuah website akan menarik pengguna apabila tampilan website bagus, mudah, dan membuat pengguna nyaman saat mengaksesnya.

Perpustakaan Pusat Universitas Padjadjaran menghadirkan website Kandaga sebagai bentuk pelayanan perpustakaan digital. Perpustakaan digital (digital library) adalah kumpulan sumber daya informasi dan konten dalam bentuk digital, di mana pengguna dapat mengaksesnya melalui komputer yang terhubung internet (Hartono, 2017). Perpustakaan digital sebagai bentuk alternatif dan pelengkap koleksi berbasis cetak konvensional. Untuk itu, perpustakaan digital memberikan kepuasan pada pengguna dalam menerima pelayanan perpustakaan yang dapat menjangkau pengguna tanpa ruang dan waktu. Al-Manasra, Khair, Zaid, and Qutaishat (2013) menyebutkan bahwa kepuasan adalah penilaian evaluatif setelah produk atau jasa digunakan atau dibeli. Kepuasan juga merupakan evaluasi keseluruhan berdasarkan pengalaman keseluruhan pada barang dan jasa dari suatu perusahaan dari waktu ke waktu.

Penelitian mengenai kualitas website telah diteliti beberapa peneliti, di antaranya penelitian Warjiyono \& Hellyana (2018), Abbas (2013), dan Hasanov and Khalid (2015). Pertama, penelitian Warjiyono \& Hellyana (2018) mengenai pengukuran kualitas website menggunakan metode WebQual 4.0.
Penelitian ini menggunakan 4 (empat) instrument di antaranya, visual quality, information quality, usability quality, dan service interaction quality. Sesuai penelitian ini, diperoleh hasil bahwa visual quality, information quality, dan usability quality berpengaruh signifikan terhadap kepuasan pengguna.

Kedua, penelitian Abbas (2013) mengenai pengukuran kepuasan mahasiswa pada website. Penelitian ini mengukur kepuasan menggunakan dimensi kualitas kegunaan, kualitas interaksi pelayanan, dan kualitas informasi. Hasil penelitian ini menunjukkan bahwa dimensi kualitas kegunaan, kualitas interaksi pelayanan, dan kualitas informasi merupakan faktor yang memengaruhi kepuasan pengguna.

Ketiga, penelitian Hasanov and Khalid (2015) mengenai pengaruh kualitas situs website terhadap niat konsumen untuk membeli makanan organik secara online melalui kepuasan pelanggan sebagai variabel mediasi. Hasil penelitian menunjukkan bahwa kualitas situs website hanya berpengaruh $7 \%$ pada niat pembelian online makanan organik. Kualitas website mempunyai pengaruh positif pada kepuasan pelanggan. Penelitian ini memberikan kontribusi dalam penggunaan metode WebQual yang digunakan untuk mengukur kualitas website sehingga memperkuat peneliti dalam pemilihan metode WebQual.

Berdasarkan penelitian terdahulu di atas, kualitas website ternyata memiliki hubungan dengan kepuasan pengguna. Adapun kebaruan penelitian ini dengan penelitian terdahulu adalah penambahan dimensi pada kualitas website antara lain kualitas antarmuka dan kualitas pelayanan perpustakaan digital. Desain tampilan antarmuka memudahkan 
pengembang website untuk membuat situs yang menarik pengguna agar mudah menggunakannya. Selain itu, penggunaan desain tampilan antarmuka yang userfriendly akan membuat pengguna nyaman sehingga tidak perlu merasa terganggu ketika menggunakannya.

Dengan demikian, peneliti tertarik meneliti mengenai pengaruh kualitas website Kandaga terhadap kepuasan pengguna Perpustakaan Pusat Universitas Padjadjaran. Penelitian ini bertujuan untuk mengetahui pengaruh kualitas kegunaan website, pengaruh kualitas informasi website Kandaga, pengaruh kualitas interaksi pelayanan website Kandaga, pengaruh kualitas antarmuka website Kandaga, dan pengaruh kualitas pelayanan perpustakaan digital website Kandaga terhadap kepuasan pengguna.

\section{METODE PENELITIAN}

Penelitian ini menggunakan pendekatan kuantitatif yang bersifat eksplanatori, yaitu pendekatan yang dapat memperkirakan hubungan sebab akibat antar variabel. Peneliti dalam penelitian ini meneliti kualitas website dan kepuasan pengguna. Peneliti melihat bahwa jumlah populasi sangat besar sehingga memerlukan data statistik untuk menghasilkan kesimpulan yang dapat peneliti jelaskan. Penelitian kuantitatif adalah pendekatan deduktif menggunakan statistik dan populasi yang luas dalam merekam data. Penelitian kuantitatif ini bersifat penjelasan (explanatory), yaitu menjelaskan hubungan sebab akibat variabel penyebab dan variabel akibat.

Peneliti meneliti pengaruh kualitas website Kandaga terhadap kepuasan pengguna Perpustakaan Pusat Universitas Padjadjaran pada November 2019 sampai
Mei 2020. Pada tabel 1, variabel operasional penelitian dalam penelitian ini terdapat lima variabel $\mathrm{X}$ dan satu variabel Y. Indikator instrumen variabel kualitas website diukur menggunakan dimensi WebQual 4.0 berupa kualitas interaksi pelayanan, kualitas informasi, dan kualitas kegunaan, dengan penambahan variabel kualitas antarmuka, kualitas pelayanan perpustakaan digital, dan indikator instrumen variabel $\mathrm{Y}$ adalah kepuasan pengguna (Arifin, Nugroho, \& Hantono, 2015; Schlatter \& Levinson, 2013; GómezCruz, Harari-Betancourt, \& VergaraMendoza, 2020).

Perpustakaan Pusat Universitas Padjadjaran dari Oktober 2018 menggunakan Google Analytic untuk melihat tingkat penggunaan website Kandaga. Tingkat penggunaan website Kandaga dari Oktober 2018 sampai November 2019 adalah 35.325 kunjungan. Objek penelitian ini adalah sivitas akademika Universitas Padjadjaran yang menggunakan website Kandaga melalui login ke https://paus.unpad.ac.id/ dalam periode waktu Oktober 2018 sampai Desember 2019 sejumlah 5.478 orang. Maka, populasi penelitian sebanyak 5.478 orang.

Peneliti mengambil sampel penelitian menggunakan proportionate stratified random sampling, yaitu sebuah teknik penarikan sampel dengan populasi yang heterogen dan berstrata proporsional. Sampel yang terpilih mencerminkan keragaman populasi di 16 fakultas di Universitas Padjadjaran. Adapun peneliti dalam menentukan ukuran sampel menggunakan rumus Yamane, yang diketahui jumlah sampel 373 orang. Rumus ini digunakan jika jumlah populasi penelitian sudah diketahui (Rabathy, 2018). Setelah sampel 
diketahui, peneliti mengumpulkan data menggunakan wawancara, observasi, dan kuesioner pada pada 373 responden melalui penyebaran kuesioner secara offline dan online. Kuesioner menggunakan skala Likert mengenai kualitas website sebanyak 35 butir pernyataan dan 9 pernyataan tentang kepuasan pengguna.

Peneliti setelah berhasil mengumpulkan kuesioner, maka peneliti melakukan uji reliabilitas, uji validitas, dan uji asumsi klasik terhadap data yang diperoleh. Pertama, uji reliabilitas pada kuesioner dengan pertanyaan penelitian yang telah terbukti valid menggunakan metode Cronbach's Alpha. Jika (1) nilai Alpha $\geq 0.70$, maka kuesioner tersebut reliabel; (2) nilai Alpha < 0.70, maka kuesioner tersebut tidak reliabel. Nilai Cronbach's Alpha variabel X lebih besar dari 0,70, maka hasil keputusan adalah pernyataan instrumen dalam variabel $X$ dinyatakan reliabel. Nilai Cronbach's Alpha variabel kepuasan pengguna sebesar 0,914. Nilai tersebut lebih besar dari 0,70, di mana $0,914>0,70$. Untuk itu, hasil keputusannya adalah instrumen dalam variabel kepuasan pengguna dinyatakan reliabel.

Kedua, uji validitas kuesioner menggunakan metode Pearson Product Moment Correlation. Uji validitas terhadap variabel kualitas website diperoleh skor bahwa $\mathrm{r}_{\text {hitung }}$ lebih besar dari $\mathrm{r}_{\text {tabel, }}$ artinya semua pernyataan variabel kualitas website valid. Hasil uji validitas variabel kepuasan pengguna diperoleh bahwa $\mathrm{r}_{\text {hitung }}$ lebih besar dari $\mathrm{r}_{\text {tabel, }}$ artinya semua pernyataan variabel kepuasan pengguna valid.

Ketiga, uji asumsi klasik yang digunakan ialah uji normalitas data. Uji normalitas data pada penelitian ini berdistribusi normal dengan nilai residual membentuk kurva bel dan mengikuti garis sumbu $X$ sehingga persyaratan yang diharuskan dalam model regresi ini layak atau benar. Penggunaan uji Kolmogorov Smirnov untuk melihat pengujian normalitas residual menunjukkan nilai Sig. $=0.66$, lebih besar dari $\propto=5 \%$ sehingga $\mathrm{H}_{0}$ diterima, artinya asumsi normalitas residual telah terpenuhi.

Uji asumsi klasik berikutnya yang adalah non-multikolinearitas. Asumsi ini dipenuhi apabila nilai Variance Inflation Factor (VIF) seluruhnya lebih kecil dari 10. Hasil pengujian yang diperoleh adalah seluruh nilai VIF yang diperoleh lebih kecil dari 10 sehingga dapat disimpulkan bahwa tidak ada pelanggaran asumsi multikolinearitas.

Kemudian, uji asumi klasik lainnya ialah uji heteroskedastisitas yang terdeteksi tidak adanya gejala heterokedastisitas. Hal ini diketahui dari titik-titik penyebar di atas dan bawah atau sekitar angka nol. Titik-titik tidak mengumpul di salah satu bagian, namun titik-titik data menyebar tidak membentuk pola tertentu. Adapun hasil uji homoskedastisitas menunjukan bahwa kualitas kegunaan memiliki nilai Sig.= 0.639, kualitas informasi memiliki nilai Sig. $=0.294$, kualitas interaksi layanan memiliki nilai Sig. $=0.441$, kualitas antarmuka memiliki nilai Sig. $=0.907$, kualitas pelayanan perpustakaan digital memiliki nilai Sig. $=0.805$. Nilai Sig. pada seluruh variabel bebas lebih besar dari $\alpha=5 \%$ sehingga dapat disimpulkan bahwa varians dari nilai residual adalah homogen dan asumsi homoskedastisitas terpenuhi.

Berdasarkan hasil uji klasik yang dilakukan, tidak terdapat masalah autokorelasi. Metode pengujian menggunakan uji Durbin Watson dengan nilai $=1.685$ terletak di antara -2 dan 2 
sehingga asumsi non autokorelasi telah terpenuhi. Asumsi terakhir yang harus dipenuhi adalah linearitas. Asumsi ini terpenuhi karena pada pengujian asumsi normalitas residual dan homoskedastisitas telah terpenuhi. Setelah seluruh asumsi terpenuhi, maka dapat dilakukan langkah selanjutnya yaitu pengujian parameter.

Hipotesis mayor penelitian ini di antaranya.

$\mathrm{H}_{0}$ : Kualitas website Kandaga tidak memiliki pengaruh signifikan terhadap kepuasan pengguna Perpustakaan Pusat Universitas Padjadjaran

$\mathrm{H}_{1}$ : Kualitas website Kandaga memiliki pengaruh signifikan terhadap kepuasan pengguna Perpustakaan Pusat Universitas Padjadjaran

Hipotesis minor penelitian ini ada lima variabel bebas dengan hipotesis pertama di bawah ini.

$\mathrm{H}_{01}$ ： Kualitas kegunaan website Kandaga tidak memiliki pengaruh positif terhadap kepuasan pengguna Perpustakaan Pusat Universitas Padjadjaran

$\mathrm{H}_{11}$ : Kualitas kegunaan website Kandaga memiliki pengaruh positif terhadap kepuasan pengguna Perpustakaan Pusat Universitas Padjadjaran

$\mathrm{H}_{02}$ : Kualitas informasi website Kandaga tidak memiliki pengaruh positif terhadap kepuasan pengguna Perpustakaan Pusat Universitas Padjadjaran

$\mathrm{H}_{12}$ : Kualitas informasi website Kandaga memiliki pengaruh positif terhadap kepuasan pengguna Perpustakaan Pusat Universitas Padjadjaran

$\mathrm{H}_{03}$ : Kualitas interaksi pelayanan website Kandaga tidak memiliki pengaruh positif terhadap kepuasan pengguna Perpustakaan Pusat
Universitas Padjadjaran

$\mathrm{H}_{13}$ : Kualitas interaksi pelayanan website Kandaga memiliki pengaruh positif terhadap kepuasan pengguna Perpustakaan Pusat Universitas Padjadjaran

$\mathrm{H}_{04}$ : Kualitas antarmuka website pengguna Kandaga tidak memiliki pengaruh positif terhadap kepuasan pengguna Perpustakaan Pusat Universitas Padjadjaran

$\mathrm{H}_{14}$ : Kualitas antarmuka pengguna website Kandaga memiliki pengaruh positif terhadap kepuasan pengguna Perpustakaan Pusat Universitas Padjadjaran

$\mathrm{H}_{05}$ : Kualitas pelayanan perpustakaan digital website Kandaga tidak memiliki pengaruh positif terhadap kepuasan pengguna Perpustakaan Pusat Universitas Padjadjaran

$\mathrm{H}_{15}$ : Kualitas pelayanan website Kandaga memiliki pengaruh positif terhadap kepuasan pengguna Perpustakaan Pusat Universitas Padjadjaran.

Tabel 2

Hasil analisis korelasi/tingkat hubungan variabel X

\begin{tabular}{lll}
\hline $\begin{array}{l}\text { Hubungan antar } \\
\text { variabel }\end{array}$ & Nilai & $\begin{array}{l}\text { Tingkat } \\
\text { hubungan }\end{array}$ \\
\hline X $_{1}$ dengan $\mathrm{X}_{2}$ & 0,815 & Sangat kuat \\
X $_{1}$ dengan $\mathrm{X}_{3}$ & 0,769 & Kuat \\
& & \\
X $_{1}$ dengan $\mathrm{X}_{4}$ & 0,787 & Kuat \\
X $_{1}$ dengan $\mathrm{X}_{5}$ & 0,742 & Kuat \\
X $_{2}$ dengan $\mathrm{X}_{3}$ & 0,812 & Sangat kuat \\
X $_{2}$ dengan $\mathrm{X}_{4}$ & 0,811 & Sangat kuat \\
X $_{2}$ dengan $\mathrm{X}_{5}$ & 0,781 & Kuat \\
X $_{3}$ dengan $\mathrm{X}_{4}$ & 0,778 & Kuat \\
X $_{3}$ dengan $\mathrm{X}_{5}$ & 0,829 & Sangat kuat \\
X $_{4}$ dengan X $_{5}$ & 0,777 & Kuat \\
\hline
\end{tabular}

Sumber: hasil pengolahan peneliti, 2020 
Untuk itu, penelitian ini menggunakan lima variabel $X$ dengan variabel $X_{1}$ adalah kualitas kegunaan, $X_{2}$ adalah kualitas informasi, variabel $X_{3}$ adalah kualitas interaksi pelayanan, variabel $X_{4}$ adalah kualitas antarmuka, $X_{5}$ adalah kualitas pelayanan perpustakaan digital, sedangkan variabel $\mathrm{Y}$ adalah kepuasan pengguna. Selanjutnya peneliti menggunakan tabel Anova pada tabel 3, untuk menghitung koefisien jalur secara simultan. Hal ini untuk melihat pengaruh variabel kualitas website $(\mathrm{X})$ secara simultan terhadap variabel kepuasan pengguna $(Y)$. Pada tabel Anova diperoleh nilai $F$ sebesar 479,175 dengan nilai probabilitas $(\mathrm{sig})=0,000$. Nilai Sig < 0,05, maka keputusannya adalah Ho ditolak dan $\mathrm{H}_{1}$ diterima.

Tabel 3

Anova

\begin{tabular}{llllll}
\hline Model & $\begin{array}{l}\text { Sum of } \\
\text { squares }\end{array}$ & $\begin{array}{l}\text { Mean } \\
\text { Square }\end{array}$ & f & Sig. \\
\hline $1 \begin{array}{l}\text { Regressio } \\
n\end{array}$ & 213.152 & 42.63 & 479, & $.000^{\mathbf{b}}$ \\
& $\begin{array}{l}\text { Residual } \\
\text { Total }\end{array}$ & 30.782 & 0.089 & & \\
\hline
\end{tabular}

Sumber: Hasil pengolahan peneliti, 2020

Hasil keputusan dari perhitungan statistik tersebut berarti kualitas website Kandaga berupa kualitas kegunaan, kualitas interaksi layanan, kualitas informasi, kualitas antarmuka, dan kualitas pelayanan perpustakaan digital berpengaruh secara simultan dan signifikan terhadap kepuasan pengguna Perpustakaan Pusat Universitas Padjadjaran. Kemudian, peneliti menganalisis data melalui analisis jalur (path analysis) menggunakan SPSS versi 21.

\section{HASIL DAN PEMBAHASAN}

Penelitian ini mendapatkan data dari sumber primer melalui kuesioner dengan menyebarkan pernyataan penelitian ke-16 fakultas di Universitas Padjadjaran dengan jumlah responden sebanyak 373 orang. Gambaran secara umum responden yang dipilih sesuai jenis kelamin, usia, asal fakultas, dan tahun masuk universitas pada tabel 4. Adapun sumber sekunder diperoleh dari laporan catatan arsip Perpustakaan pusat Universitas Padjadjaran.

Komposisi responden berdasarkan usia didominasi usia 19-24, yang didominasi mahasiswa Sarjana (S-1). Responden terbanyak dari kalangan mahasiswa karena sosialisasi dan bimbingan pengguna tentang website Kandaga dilakukan pada mahasiswa jenjang ini. Responden terbanyak berasal dari Fakultas Ilmu Komunikasi (FIKOM) sejumlah 13,1\% dan Fakultas Matematika dan Ilmu Pengetahuan Alam (FMIPA) sejumlah $12,3 \%$. Responden paling banyak dari kedua fakultas ini karena mahasiswanya telah secara kontinu menerima sosialisasi dan bimbingan pemakai perpustakaan (user education).

Perpustakaan dalam kegiatan bimbingan pemakai antara lain berisi kegiatan pengenalan perpustakaan pusat dan fakultas, juga pengenalan fasilitas online perpustakaan, contohnya website Kandaga. Ada beberapa fakultas yang telah menerima kegiatan bimbingan pemakai perpustakaan. Fakultas Ilmu Budaya (FIB), Fakultas Kedokteran Gigi (FKG), Fakultas Ilmu Sosial dan Ilmu Politik (FISIP), dan Fakultas Ekonomi dan Bisnis (FEB) telah menerima materi bimbingan pemakai perpustakaan, namun hanya materi pengenalan perpustakaan fakultas saja. Adapun Fakultas Pertanian pun telah menerima kegiatan bimbingan pemakai perpustakaan dan sosialisasi website Kandaga, akan tetapi sejak 2019 kegiatan ini tidak dilakukan lagi. 
Adapun komposisi responden berdasarkan tahun masuk yang memiliki jumlah terbanyak adalah mahasiswa mahasiswa angkatan 2018. Apabila responden dilihat dari hasil penelitian, persentase responden tidak berbeda jauh berbeda. Maka responden dari semua angkatan dianggap secara merata menggunakan website Kandaga. Berdasarkan hasil penelitian pun diperoleh data responden angkatan 2015 paling sedikit karena sebagian besar mahasiswa angkatan 2015 telah lulus. Penelitian mengenai pengaruh kualitas website Kandaga terhadap kepuasan pengguna Perpustakaan Pusat Universitas Padjadjaran dianalisis peneliti dalam variabel pengaruh kualitas website Kandaga secara simultan, pengaruh kualitas kegunaan website, pengaruh kualitas informasi website Kandaga, pengaruh kualitas interaksi pelayanan website Kandaga, pengaruh kualitas antarmuka website Kandaga, dan pengaruh kualitas pelayanan perpustakaan digital pada website Kandaga terhadap kepuasan pengguna.

Variabel kualitas kegunaan dalam penelitian ini menggunakan tujuh indikator. Sesuai analisa deskriptif, kemudahan navigasi merupakan indikator yang bernilai paling rendah sebesar $64,8 \%$ dan tampilan website sebesar $64,8 \%$. Nilai tertinggi terdapat pada pernyataan website Kandaga mengandung nilai manfaat sebesar 77,1\%. Berdasarkan hal ini, website Kandaga bernilai nilai manfaat karena memberikan informasi yang dibutuhkan sivitas akademika.

Variabel kualitas informasi dalam penelitian ini menggunakan tujuh pernyataan. Nilai terendah diperoleh pada pernyataan website Kandaga menyediakan informasi yang tepat waktu sebesar 64\%, dan website Kandaga menyediakan informasi yang cukup detail sebesar 64,3\%. Adapun nilai tertinggi terdapat pada pernyataan website Kandaga menyediakan informasi yang mudah dipahami sebesar $72,3 \%$.

Variabel kualitas interaksi dalam penelitian ini menggunakan tujuh indikator. Nilai terendah diperoleh pada pernyataan adanya suasana komunitas di website Kandaga sebesar 49,5\% dan nilai tertinggi pada pernyataan pengguna website Kandaga merasa aman terhadap informasi pribadi sebesar 70,8\%.

Variabel kualitas antarmuka dalam penelitian ini menggunakan delapan indikator. Nilai terendah diperoleh pada pernyataan website Kandaga menyediakan informasi apa yang sedang berlangsung (feedback) dalam waktu yang tepat, misalnya website memberikan informasi jika sistem bermasalah atau ada kesalahan dari pengguna sebesar 59\%. Nilai tertinggi terdapat pada pernyataan website Kandaga menggunakan huruf (font) yang sesuai sebesar 73,5\% dan website Kandaga menggunakan warna yang sesuai sebesar $73,2 \%$.

Variabel pengaruh kualitas pelayanan perpustakaan digital dan variabel kepuasan pengguna pada website Kandaga menggunakan enam indikator. Nilai terendah diperoleh pada pernyataan responden yang tidak akan beralih menggunakan website lain untuk memperoleh informasi sebesar $47 \%$. Nilai tertinggi terdapat pada pernyataan kesediaan menggunakan kembali website Kandaga sebesar 67,8\%.

Adapun besaran pengaruh kualitas website kandaga berupa kualitas kegunaan, kualitas interaksi layanan, kualitas informasi, kualitas antarmuka, dan kualitas pelayanan perpustakaan digital 


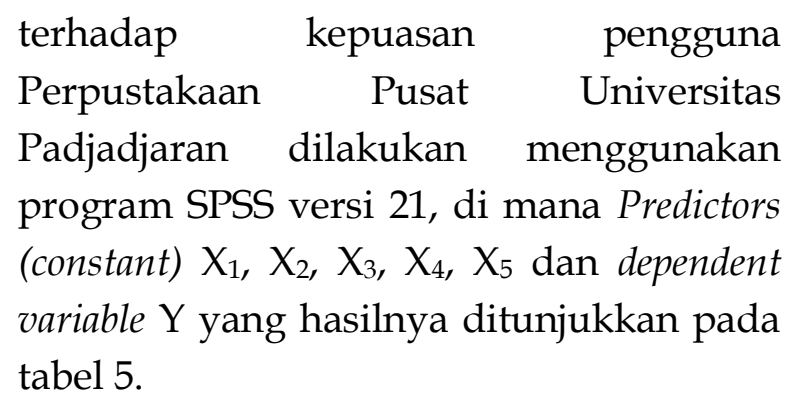

Tabel 5

Besaran pengaruh variabel $X$ secara simultan terhadap Y berupa model summary

\begin{tabular}{|c|c|c|c|c|}
\hline Model & $\mathbf{R}$ & $\begin{array}{l}\mathrm{R} \\
\text { square }\end{array}$ & $\begin{array}{l}\text { Adjuste } \\
\mathrm{d} \\
\mathrm{R} \\
\text { square }\end{array}$ & $\begin{array}{l}\text { Std error } \\
\text { of the } \\
\text { estimate }\end{array}$ \\
\hline 1 & .935 & .874 & .872 & .2983 \\
\hline
\end{tabular}

Berdasarkan tabel 5, kualitas website $(X)$ berpengaruh secara simultan terhadap kepuasan pengguna (Y) Perpustakaan Pusat Universitas Padjadjaran sebesar 0,874 atau $87,4 \%$ dan sisanya sebesar $12,6 \%$ dipengaruhi variabel lain yang tidak dijelaskan dalam penelitian ini. Hasil perhitungan statistik ini menunjukkan bahwa kualitas website Kandaga memiliki pengaruh terhadap kepuasan pengguna Perpustakaan Pusat Universitas Padjadjaran.

Hal ini mengandung arti bahwa kualitas website berdampak nyata terhadap kepuasan pengguna. Jika kualitas website secara simultan dibangun dengan lebih baik, maka tingkat kepuasan pengguna website Kandaga Perpustakaan Pusat Universitas Padjadjaran juga akan semakin tinggi. Kualitas website yang semakin tinggi, maka kepuasan pengguna pun akan semakin tinggi. Kualitas website yang dikelola dengan baik akan memberikan kontribusi pada kepuasan pengguna dan selanjutnya akan membuat loyal pengguna.

Kepuasan (satisfaction) pengguna perpustakaan merupakan kriteria yang menunjukkan kepuasan pengguna terhadap kegunaan website perpustakaan, sumber elektronik, fungsi dan pelayanan yang ditawarkan. Sistem aplikasi atau informasi yang berhasil akan meningkatkan kepuasan pengguna sehingga pengguna akan lebih sering menggunakan sistem aplikasi tersebut (Prasetiyo \& Priyadi, 2018).

Kualitas website memiliki pengaruh terhadap kepuasan pengguna. Hal ini berarti bahwa media lebih besar dalam memengaruhi alam bawah sadar kita. Karakteristik media di penelitian ini digambarkan sebagai kualitas website yang berdampak atau memengaruhi seseorang, yakni kepuasan pengguna. Berkaitan dengan karakteristik website, Visuwords (2021) menyatakan bahwa sinonim dari karakteristik adalah kualitas. Efek pesan yang disampaikan melalui website telah memberikan efek besar kepada masyarakat sehingga memengaruhi persepsi manusia, khususnya kepuasan pengguna. Semakin baik kualitas website, semakin tinggi pula kepuasan pengguna dan begitu pun sebaliknya. Pada akhirnya, pengguna website Kandaga akan tetap setia dan loyal.

Hasanov and Khalid menemukan bahwa kualitas website memiliki pengaruh penting pada kepuasan pelanggan. Website yang berkualitas, maka pelanggan cenderung lebih sering menggunakan website. Temuan penelitian lain mengidentifikasi bahwa salah satu faktor pendorong utama kepuasan pelanggan adalah kualitas website (Hsu, Chang, \& Chen, 2012). 
Tabel 6

Nilai koefisien jalur individu

\begin{tabular}{|c|c|c|c|}
\hline Model & & $\begin{array}{l}\text { Standardized } \\
\text { coefisients } \\
\text { beta }\end{array}$ & Sig. \\
\hline \multirow[t]{9}{*}{1} & (Constant) & & .000 \\
\hline & $\begin{array}{l}\text { Kualitas } \\
\text { keounaan }\end{array}$ & .072 & .049 \\
\hline & Kualitas & .045 & \\
\hline & informasi & & .267 \\
\hline & Kualitas & .253 & .000 \\
\hline & interaksi & & \\
\hline & pelayanan & & \\
\hline & $\begin{array}{l}\text { Kualitas } \\
\text { antarmuka }\end{array}$ & .106 & .005 \\
\hline & $\begin{array}{l}\text { Kualitas } \\
\text { perpustaka } \\
\text { an digital }\end{array}$ & .526 & .000 \\
\hline
\end{tabular}

Berdasarkan penelitian ini dapat digambarkan analisis jalurnya sebagai berikut.

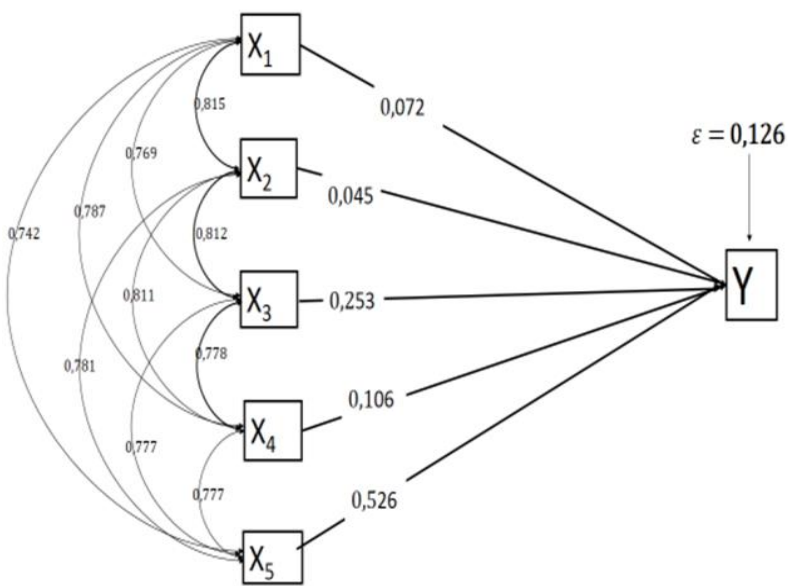

Gambar 1. Model hasil perhitungan diagram jalur pengaruh kualitas website Kandaga terhadap kepuasan pengguna

Sumber: Hasil pengolahan peneliti, 2020

Peneliti setelah melakukan perhitungan dan mendapatkan nilai analisis jalur pada tabel 6, maka persamaan struktural untuk diagram jalur penelitian ini adalah

$Y=0,072 X_{1}+0,045 X_{2}+0,253 X_{3}+0,106 X$ $+0,526 \mathrm{X}_{5}+0,126$. Pengaruh variabel $\mathrm{X}$ terhadap variabel $\mathrm{Y}$ dilihat dari nilai signifikan pada tabel 6 jika kurang atau sama dengan 5\% maka variabel $X$ berpengaruh signifikan terhadap variabel Y. Berdasarkan tabel 6, terlihat bahwa pada kolom Sig (signifikan) kualitas kegunaan $\left(\mathrm{X}_{1}\right)$ didapat nilai Sig. sebesar 0,049, maka Ho ditolak dan $\mathrm{H}_{1}$ diterima, artinya koefisien jalur adalah signifikan. Hasil uji menunjukkan bahwa kualitas kegunaan berpengaruh signifikan terhadap kepuasan pengguna website Kandaga Perpustakaan Pusat Universitas Padjadjaran. Adapun pengaruh kualitas kegunaan $\left(X_{1}\right)$ memiliki pengaruh sebesar 0,072 atau $7,2 \%$ terhadap kepuasan pengguna $(\mathrm{Y})$.

Media website berdampak pada kehidupan manusia. Website memungkinkan orang untuk mengakses dan berbagi informasi di seluruh dunia. Individu melihat isi pesan website, kemudahan penggunaan, tampilan yang menarik, dan pengalaman positif ketika menggunakan website akan berpengaruh terhadap kepuasan pengguna. Kualitas kegunaan website yang baik akan meningkatkan kepuasan pengguna sehingga pengguna mempunyai niat untuk menggunakan website kembali. Kemudahan website berarti bahwa semua orang bahkan penyandang cacat dapat mudah mengerti, memahami, menavigasi, berinteraksi dengan website dan mereka dapat memberikan kontribusi pada website tersebut (Yang, Zhao, Liu, \& Bielefield, 2020).

Pengguna cenderung menggunakan sistem teknologi jika sistem mudah digunakan dan memberikan manfaat. Bagi pengguna, kualitas kegunaan dan kemudahan secara signifikan memengaruhi sikap terhadap sistem informasi yang akhirnya akan 
memengaruhi kepuasan pengguna. Ong, Chang, and Lee (2013) menyatakan bahwa kemanfaatan (usefulness) dan kemudahan penggunaan sistem secara positif berhubungan terhadap kepuasan pengguna.

Zamani, Sunarto, and Mastan (2016) mengatakan bahwa hasil pada dimensi kualitas kegunaan memiliki pengaruh positif terhadap kepuasan pengguna. Berdasarkan paparan tentang kualitas kegunaan dan kepuasan pengguna yang didukung dari berbagai rujukan, maka dapat disimpulkan bahwa kualitas kegunaan memiliki pengaruh yang signifikan terhadap kepuasan pengguna website Kandaga Perpustakaan Pusat Universitas Padjadjaran.

Sesuai tabel 6, terlihat pada kolom Sig (signifikan) kualitas informasi $\left(\mathrm{X}_{2}\right)$ didapat nilai sig. sebesar 0,267, maka Ho diterima dan $\mathrm{H}_{1}$ ditolak, artinya koefisien jalur adalah tidak berpengaruh signifikan. Hasil uji menunjukkan kualitas informasi tidak berpengaruh signifikan terhadap kepuasan pengguna website Kandaga Perpustakaan Pusat Universitas Padjadjaran. Selain itu, variabel kualitas informasi $\left(X_{2}\right)$ memiliki pengaruh sebesar 4,5\% terhadap kepuasan pengguna $(\mathrm{Y})$. Dari perhitungan statistik tersebut, dapat disimpulkan bahwa kualitas informasi sebagai salah satu pembentuk kualitas website tidak berpengaruh secara signifikan terhadap kepuasan pengguna Kandaga Perpustakaan Pusat Universitas Padjadjaran.

Saat ini, berdasarkan hasil penelitian kualitas informasi tidak memberikan dampak signifikan pada kepuasan pengguna perpustakaan. Hal ini bukan berarti kualitas informasi tidak penting. Hasil analisis deskriptif diperoleh bahwa nilai variabel kualitas informasi website
Kandaga paling tinggi dibandingkan variabel lain.

Pengguna website Kandaga percaya bahwa kualitas informasi website Kandaga saat ini telah dapat memenuhi kebutuhan pengguna. Website Kandaga mempunyai reputasi yang baik, dapat dipercaya, relevan, detail dan mudah dimengerti. Informasi yang diperoleh dapat dipercaya, artinya informasi yang tersedia valid, relevan, berguna, dan sesuai. Adapun terkait temuan kualitas informasi, dalam penelitian Khairrunnisa and Yunanto (2017), menemukan bahwa kualitas informasi tidak berpengaruh terhadap kepuasan pengguna. Kualitas informasi yang baik akan memengaruhi persepsi manusia dalam hal ini kepuasan pengguna.

Kualitas interaksi pelayanan pada kolom Sig (signifikan) didapat nilai sig. sebesar 0,000, maka Ho ditolak dan $\mathrm{H}_{1}$ diterima, artinya koefisien jalur adalah berpengaruh signifikan. Hasil uji menunjukkan kualitas interaksi pelayanan berpengaruh signifikan terhadap kepuasan pengguna website Kandaga Perpustakaan Pusat Universitas Padjadjaran. Kualitas interaksi pelayanan $\left(X_{3}\right)$ memiliki pengaruh 25,3\% terhadap kepuasan pengguna $(\mathrm{Y})$.

Pengaruh kualitas interaksi pelayanan terhadap kepuasan pengguna sebesar 25,3\% menunjukkan bahwa kualitas interaksi pelayanan yang baik akan memengaruhi persepsi manusia yaitu kepuasan pengguna. Karakteristik unik yang digambarkan sebagai kualitas interaksi pelayanan website akan berdampak pada seseorang, yang terdiri dari reputasi website, keamanan ketika menggunakan website, keamanan informasi pribadi, komunikasi dengan organisasi, dan pelayanan sesuai yang 
dijanjikan akan berdampak pada kepuasan pengguna. Adapun kualitas interaksi pelayanan media website lebih penting daripada isi pesan. Hal ini akan membentuk persepsi kepuasan pengguna. Kualitas interaksi pelayanan yang baik akan meningkatkan kepuasan pengguna.

Penelitian tentang kualitas interaksi pelayanan juga dilakukan Monalisa (2016), yang menemukan bahwa kepuasan pengguna paling besar dipengaruhi dimensi kualitas interaksi pelayanan. Napitupulu (2016) memperkuat penelitian tentang adanya hubungan dan pengaruh antara kualitas interaksi pelayanan dan kepuasan pengguna. Begitu pun Zamani et al. (2016) berpendapat bahwa setiap peningkatan kualitas interaksi pelayanan pada website akan meningkatkan kepuasan pengguna. Penyediaan fasilitas komunikasi atau pelayanan interaktif dapat membantu memperbaiki kualitas pelayanan pada website perpustakaan dan membantu memperbaiki kepuasan pengguna.

Kualitas antarmuka pada kolom Sig (signifikan) didapatkan nilai sig. sebesar 0,005, maka Ho ditolak dan $\mathrm{H}_{1}$ diterima, artinya koefisien jalur berpengaruh signifikan. Hasil uji menunjukkan bahwa kualitas antarmuka berpengaruh signifikan terhadap kepuasan pengguna website Kandaga Perpustakaan Pusat Universitas Padjadjaran. Secara keseluruhan, kualitas antarmuka $\left(X_{4}\right)$ memiliki pengaruh sebesar $10,6 \%$ terhadap kepuasan pengguna $(\mathrm{Y})$.

Seorang individu melihat isi pesan website, warna, desain, link yang bekerja baik, kecepatan dan ketepatan, font, tata letak yang terstruktur, dan konsisten pada website sehingga akan berpengaruh terhadap kepuasan pengguna. Meyrowitz (2019) menyatakan bahwa teori medium berfokus pada bagaimana karakteristik setiap media komunikasi memiliki pengaruh yang tidak dapat berkurang ke sifat isi pesan media. Begitu pun dengan website Kandaga yang memiliki karakter sesuai tri dharma perguruan tinggi antara lain pendidikan, penelitian, dan pengabdian masyarakat.

Lule and Liani (2014) berpendapat bahwa kepuasan pengguna dan kepercayaan pelanggan dipengaruhi kualitas antarmuka. Kualitas antarmuka yang menarik dapat membuat pelanggan merasa percaya untuk memutuskan melakukan transaksi. Berdasarkan perhitungan statistik tabel 6, dapat diambil kesimpulan bahwa kualitas antarmuka pengguna sebagai salah satu pembentuk kualitas website yang berpengaruh signifikan terhadap kepuasan pengguna Kandaga Perpustakaan Pusat Universitas Padjadjaran.

Kualitas pelayanan perpustakaan digital pada kolom Sig (signifikan) didapatkan nilai sig. sebesar 0,005, maka Ho ditolak dan H1 diterima, artinya koefisien jalur berpengaruh signifikan. Hasil uji menunjukkan bahwa kualitas pelayanan perpustakaan digital berpengaruh signifikan terhadap kepuasan pengguna website Kandaga Perpustakaan Pusat Universitas Padjadjaran. Pengaruh total kualitas layanan digital library $\left(\mathrm{X}_{5}\right)$ memiliki pengaruh sebesar 0,526 atau 52,6\% terhadap kepuasan pengguna (Y), artinya bahwa apabila kualitas pelayanan perpustakaan digital ditingkatkan, maka kepuasan pengguna akan meningkat.

Adapun kontribusi pengaruh paling besar pada kepuasan pengguna ditemukan pada variabel kualitas pelayanan perpustakaan digital. Sesuai wawancara yang dilakukan untuk memperkuat hasil 
temuan ini, sivitas akademika mengakses website Kandaga bertujuan untuk mencari dokumen dan informasi artikel ilmiah, dari jurnal milik Universitas Padjadjaran atau jurnal yang dilanggan, dan karya tulis ilmiah, seperti pernyataan dua responden di bawah ini.

"Saya mengakses website Kandaga ingin mencari jurnal sebagai literatur dalam penulisan skipsi-ku" (E. Marhamah, wawancara, March 5, 2020).

“Aku nyari artikel jurnal di website Kandaga untuk membantu penelitian tugas akhir" (R. Ermawati, wawancara, March 20, 2020).

Pengaruh kualitas pelayanan perpustakaan digital terhadap kepuasan pengguna sebesar 52,6\%. Hal ini menunjukkan bahwa kualitas pelayanan perpustakaan digital yang baik akan memengaruhi persepsi manusia, yakni kepuasan pengguna. Medium dalam hal ini website Kandaga, telah mengubah cara berpikir individu dalam mengakses informasi. Website Kandaga adalah salah satu bentuk saluran (medium) dalam komunikasi yang dapat mengubah cara berpikir individu mengenai diri sendiri dan dunianya. Saluran komunikasi atau media lebih penting daripada isi pesan dan media dapat memanipulasi gambaran mengenai masyarakat, diri sendiri, atau orang lain. Media sebagai bagian penting dan memiliki pengaruh dalam kehidupan masyarakat, sadar atau tidak sadar (Khatimah, 2018).

Sivitas akademika mengakses website Kandaga sebagai sumber referensi untuk bahan pengerjaan tugas dan menulis artikel. Hasil penelitian ini sejalan penelitian Yuliant (2017) yang menyatakan bahwa kualitas perpustakaan digital yang baik dapat membantu pengguna meningkatkan produktivitas dalam mengerjakan tugas dan pekerjaan lainnya. Adapun prioritas peningkatan dan perbaikan pada kualitas pelayanan perpustakaan digital website Kandaga perlu dilakukan Perpustakaan Pusat Universitas Padjadjaran. Variabel ini yang memiliki pengaruh paling besar terhadap kepuasan pengguna. Website Kandaga Perpustakaan Pusat Universitas Padjadjaran sudah memungkinkan pengguna untuk mengakses perpustakaan digital kapan saja. Pengguna dapat mengakses website Kandaga selama terhubung jaringan internet, memiliki kemudahan dalam menemukan informasi, dan menyediakan konten alternatif untuk pengguna berupa fasilitas pemerolehan data (download) secara langsung konten/informasi dan membaca secara online pada perpustakaan digital.

\section{SIMPULAN}

Simpulan penelitian ini adalah kualitas website Kandaga berpengaruh secara simultan terhadap kepuasan pengguna Perpustakaan Pusat Universitas Padjadjaran. Kualitas website Kandaga memiliki pengaruh yang besar terhadap kepuasan pengguna Perpustakaan Pusat Universitas Padjadjaran. Kualitas kegunaan, kualitas interaksi pelayanan, kualitas antarmuka, dan kualitas pelayanan perpustakaan digital secara parsial berpengaruh signifikan terhadap kepuasan pengguna. Hasil penelitian juga menunjukkan bahwa kualitas pelayanan perpustakaan digital merupakan variabel yang paling dominan dalam memengaruhi kepuasan pengguna. Kualitas informasi tidak memberikan dampak signifikan pada kepuasan pengguna Perpustakaan Pusat Universitas Padjadjaran. Untuk itu, 
Perpustakaan Pusat Universitas Padjadjaran perlu mengoptimalkan kualitas perpustakaan digital. Hal ini karena variabel kepuasan pengguna paling besar berpengaruh dibandingkan variabel bebas lainnya. Kepuasan pengguna website Kandaga Perpustakaan Pusat Universitas Padjadjaran dapat ditingkatkan secara bersama-sama antara kualitas kegunaan, kualitas interaksi pelayanan, kualitas informasi, kualitas antarmuka, dan kualitas pelayanan digital library. Sesuai hasil penelitian diperoleh bahwa kualitas website Kandaga secara keseluruhan memiliki pengaruh yang signifikan dan besar terhadap kepuasan pengguna. Hasil temuan tersebut telah menguatkan teori medium bahwa kualitas website memiliki pengaruh terhadap kepuasan pengguna. Rancangan penelitian selanjutnya adalah melakukan penelitian mengenai kualitas pelayanan digital library website Kandaga bertujuan untuk untuk mengetahui jurnal elektronik yang dibutuhkan dan kesulitan sivitas akademika dalam menggunakan website Kandaga.

\section{DAFTAR PUSTAKA}

Abbas, W. (2013). Analisa kepuasan mahasiswa terhadap website Universitas Negeri Yogyakarta (UNY). Prosiding Seminar Nasional Sains Dan Teknologi 4 2013, 1-6. Retrieved from https:/ / publikasiilmiah.unwahas.ac.i d/index.php/PROSIDING_SNST_FT /article/view/759/871

Al-Manasra, E. A., Khair, M., Zaid, S. A., \& Qutaishat, F. T. (2013). Investigating the impact of website quality on consumers' satisfaction in Jordanian telecommunication sector. Arab Economic and Business Journal, 8(1-2),
31-37.

https:/ / doi.org/10.1016/j.aebj.2013.1 1.004

Arifin, S. R., Nugroho, E., \& Hantono, B. S. (2015). Analisis kualitas layanan website Universitas Hasanuddin dengan metode webqual 4.0 modifikasi. Teknomatika: Jurnal Informatika Dan Komputer, 8(1), 81-92. Retrieved from https:/ / ejournal.unjaya.ac.id/index.ph p/teknomatika/article/view/444/393

Gómez-Cruz, M. E., Harari-Betancourt, V., \& Vergara-Mendoza, G. (2020). Quality indicators and user satisfaction in university libraries. Journal of Academic Librarianship, 46(6), 1-8.

https://doi.org/10.1016/j.acalib.2020. 102230

Google Analytic. (2019). Google analytic. Google. Retrieved December 20, 2019, from

https:/ /lib.unpad.ac.id/analytics/?m odule=Login $/$ diakses

Google Scholar. (2021). Google scholar. Google Scholar. Retrieved January 28, 2021, from https:/ /scholar.google.com/citations? user=73PubJoAAAAJ\&hl=en\&oi=ao/

Hartono. (2017). Strategi pengembangan perpustakaan digital dalam membangun aksesibilitas informasi: Sebuah kajian teoritis pada perpustakaan perguruan tinggi islam di Indonesia. Unilib: Jurnal Perpustakaan, 8(1), 75-91. https:/ / doi.org/10.20885/unilib.vol8. iss1.art7

Hasanov, J., \& Khalid, H. (2015). The impact of website quality on online purchase intention of organic food in Malaysia: A webqual model approach. Procedia Computer Science, 
72(30),

382-389.

https:// doi.org/10.1016/j.procs. 2015. 12.153

Hsu, C.-L., Chang, K.-C., \& Chen, M.-C. (2012). The impact of website quality on customer satisfaction and purchase intention: Perceived playfulness and perceived flow as mediators. Information Systems and E-Business Management, 10(4), 549-570. https:/ / doi.org/10.1007/s10257-0110181-5

Junaeti, \& Arwani, A. (2016). Peranan perpustakaan dalam meningkatkan kualitas perguruan tinggi: Konstruksi pelayanan, strategi, dan citra perpustakaan. Libraria: Jurnal Perpustakaan, 4(1), 27-54. https:// doi.org/10.21043/libraria.v4i 1.1245

Khairrunnisa, U., \& Yunanto, M. (2017). Pengaruh kualitas sistem terhadap kepuasan pengguna dan manfaat bersih pada implementasi e-faktur: Validasi model kesuksesan sistem informasi Delone Dan Mclean. Jurnal Ilmiah Ekonomi Bisnis, 22(3), 229-241. Retrieved from https:/ / ejournal.gunadarma.ac.id/in dex.php/ekbis/article/view/1756

Khatimah, H. (2018). Posisi dan peran media dalam kehidupan masyarakat. TASÂMUH, 16(1), 119-138. https:// doi.org/10.20414/tasamuh.v1 $6 \mathrm{i} 1.548$

Lule, B., \& Liani, M. (2014). Pengaruh pengguna antarmuka dan keamanan situs terhadap kepuasan, kepercayaan dan loyalitas pelanggan pada situs belanja online di Indonesia. JBE: Journal of Business and Economics, 13(2), 189-198. Retrieved from http:/ / ejournal.unklab.ac.id/index.p hp/jbe/article/view/24/19
Meyrowitz, J. (2019). Medium theory. John Wiley \& Sons. https:/ / doi.org/10.1002/97811189782 38.ieml0136

Monalisa, S. (2016). Analisis kualitas layanan website terhadap kepuasan mahasiswa dengan penerapan metode webqual: Studi kasus UIN Suska Riau. SiTekIn: Jurnal Sains, Teknologi Dan Industri, 13(2), 181-189. https:// doi.org/10.24014/sitekin.v13i 2.1604

Napitupulu, D. B. (2016). Evaluasi kualitas website Universitas XYZ dengan pendekatan webqual. Buletin Pos Dan Telekomunikasi, 14(1), 51-64. https:/ / doi.org/10.17933/bpostel.201 6.140105

Ong, C.-S., Chang, S.-C., \& Lee, S.-M. (2013). Website satisfaction dimentions: Factors between satisfaction and dissatisfaction. Information Development, 29(4),

299-308. https:/ / doi.org/10.1177/02666669124 66400

Prasetiyo, K., \& Priyadi, Y. (2018). Perancangan DFD berdasarkan hasil pengukuran kualitas website melalui metode webqual 4.0 pada JD.id. Jurnal RESTI: Rekayasa Sistem Dan Teknologi Informasi, 2(2), 514-521. https://doi.org/10.29207/resti.v2i2.395

Rabathy, Q. (2018). Pengaruh implementasi teknologi informasi dan iklim komunikasi terhadap efektivitas organisasi: Studi eksplanatori pada 9 kantor gerbang PT Jasa Marga (persero) tbk cabang Purbaleunyi (Disertasi) [Universitas Padjadjaran, Sumedang]. Retrieved from

http:/ / repository.unpad.ac.id/frontd oor/index/index/docId/34432

Rochmawati, I. (2019). Analisis user interface situs web iwearup.com. 
Visualita: Jurnal Online Desain Komunikasi Visual, 7(2), 31-44. https:// doi.org/10.33375/vslt.v7i2.1459

Schlatter, T., \& Levinson, D. (2013). Visual usability: Principles and practices for designing digital applications. Elsevier. Retrieved from https:/ / www.sciencedirect.com/boo k/9780123985361/visualusability\#book-description

Syaifullah, \& Soemantri, D. O. (2016). Pengukuran kualitas website menggunakan metode WEBQUAL 4.0: Studi kasus CV. Zamrud Multimedia Network. Jurnal Rekayasa Dan Manajemen Sistem Informasi, 2(1), 19-25. https:/ / doi.org/10.24014/rmsi.v2i1.16 89

Visuwords. (2021). Visuwords. Goocto.Com. Retrieved April 14, 2021, from https://visuwords.com/page/about Warjiyono, \& Hellyana, C. M. (2018). Pengukuran kualitas website pemerintah desa Jagalempeni menggunakan metode webqual 4.0. Jurnal Teknologi Informasi Dan Ilmu Komputer (JTIIK), 5(2), 139-145. https://doi.org/10.25126/jtiik.2018526 66
Wulandari, E. R., Rizal, E., \& Lusiana, E. (2020). Strategi promosi e-journal untuk generasi-z di Perpustakaan Universitas Padjadjaran. Khizanah AlHikmah: Jurnal Ilmu Perpustakaan, Informasi, Dan Kearsipan, 8(1), 11-20. https:/ / doi.org/10.24252/kah.v8i1a2 Yang, W., Zhao, B., Liu, Y. Q., \& Bielefield, A. (2020). Are ivy league library website homepages accessible? Information Technology $\mathcal{E}$ Libraries, 39(June), 1-18. https:/ / doi.org/10.6017/ital.v39i2.11 577

Yuliant, R. (2017). Pengaruh kualitas digital library berdasarkan metode digiQual terhadap kepuasan pengguna (Tesis) [Universitas Padjadjaran, Sumedang]. Retrieved from http://repository.unpad.ac.id/frontd oor/index/index/docId/34334

Zamani, U. I., Sunarto, D., \& Mastan, I. A. (2016). Analisi pengaruh kualitas website PT Badak LNG terhadap kepuasan pengguna menggunakan metode webqual 4.0. Jurnal JSIKA, 5(11), 1-8. Retrieved from https:/ /jurnal.dinamika.ac.id/index. php/jsika/article/view/1387/857 


\section{DAFTAR TABEL}

Tabel 1

Variabel operasional penelitian

\begin{tabular}{|c|c|}
\hline Variabel & Indikator \\
\hline \multirow{7}{*}{ Kualitas kegunaan $\left(\mathrm{X}_{1}\right)$} & Mudah dipelajari \\
\hline & Interaksi jelas dan dapat dimengerti \\
\hline & Mudah digunakan \\
\hline & Mudah dilakukan navigasi \\
\hline & Tampilan menarik \\
\hline & Bernilai kompetensi \\
\hline & Pengalaman positif \\
\hline \multirow{7}{*}{ Kualitas informasi $\left(\mathrm{X}_{2}\right)$} & Akurat \\
\hline & Terpercaya \\
\hline & Tepat waktu \\
\hline & Relevan \\
\hline & Mudah dimengerti \\
\hline & Detail \\
\hline & Format yang sesuai \\
\hline \multirow{7}{*}{$\begin{array}{l}\text { Kualitas interaksi pelayanan } \\
\qquad\left(\mathrm{X}_{3}\right)\end{array}$} & Reputasi yang baik \\
\hline & Transaksi aman \\
\hline & Informasi pribadi aman \\
\hline & Ruang personalisasi \\
\hline & Komunikasi dengan organisasi \\
\hline & Ruang komunitas \\
\hline & Peayanan sesuai yang dijanjikan \\
\hline \multirow{7}{*}{$\begin{array}{l}\text { Kualitas antarmuka } \\
\qquad\left(\mathrm{X}_{4}\right)\end{array}$} & Warna sesuai \\
\hline & Desain sesuai \\
\hline & Link bekerja dengan baik \\
\hline & Kecepatan dan ketepatan \\
\hline & Gambar tepat \\
\hline & Font tepat \\
\hline & Visibility of system status \\
\hline \multirow{7}{*}{$\begin{array}{l}\text { Kualitas pelayanan digital } \\
\text { Library }\left(\mathrm{X}_{5}\right)\end{array}$} & Tata letak terstruktur dan konsisten \\
\hline & Informasi seputar perpustakaan \\
\hline & Informasi pelayanan perpustakaan \\
\hline & Kebutuhan koleksi buku \\
\hline & Peminjaman buku \\
\hline & Kebutuhan karya ilmiah \\
\hline & Kebutuhan electronic journal \\
\hline \multirow{9}{*}{$\begin{array}{l}\text { Kepuasan pengguna } \\
(\mathrm{Y})\end{array}$} & $\begin{array}{l}\text { Merasa puas setelah website memberikan informasi sesuai } \\
\text { kebutuhan }\end{array}$ \\
\hline & $\begin{array}{l}\text { Merasa puas setelah website memberikan informasi sesuai } \\
\text { harapan }\end{array}$ \\
\hline & $\begin{array}{l}\text { narapan } \\
\text { Menggunakan kembali website }\end{array}$ \\
\hline & Merekomendasikan website \\
\hline & Akan menyampaikan hal positif tentang website \\
\hline & Bersedia mengunjungi website lagi \\
\hline & Merasa puas dengan kualitas pelayanan website \\
\hline & Tidak akan beralih menggunakan website lain \\
\hline & $\begin{array}{l}\text { Pernah mengalami pengalaman kurang menyenangkan } \\
\text { ketika menggunakan website }\end{array}$ \\
\hline
\end{tabular}

Sumber: Hasil pengolahan peneliti, 2020 
Tabel 4

Gambaran umum responden berdasarkan jenis kelamin, usia, asal fakultas, dan tahun masuk

\begin{tabular}{|c|c|c|c|c|}
\hline No & Gambaran responden & & f & $\%$ \\
\hline \multirow[t]{2}{*}{1} & Jenis kelamin & Laki- laki & 109 & 29,2 \\
\hline & & Perempuan & 264 & 70,8 \\
\hline \multirow[t]{5}{*}{2} & Usia & $<19$ & 74 & 19,8 \\
\hline & & $19-24$ & 261 & 70 \\
\hline & & $25-30$ & 12 & 3,2 \\
\hline & & $31-40$ & 11 & 3 \\
\hline & & $<40$ & 15 & 4 \\
\hline \multirow[t]{16}{*}{3} & Fakultas & Hukum & 25 & 6,7 \\
\hline & & Ekonomi dan Bisnis & 29 & 7,8 \\
\hline & & Kedokteran & 21 & 5,6 \\
\hline & & $\begin{array}{l}\text { Ilmu Pengetahuan } \\
\text { Alam }\end{array}$ & 46 & 12,3 \\
\hline & & Pertanian & 39 & 10,5 \\
\hline & & Kedokteran Gigi & 12 & 3,2 \\
\hline & & $\begin{array}{l}\text { Ilmu Sosial dan Ilmu } \\
\text { Politik }\end{array}$ & 19 & 5,1 \\
\hline & & Ilmu Budaya & 26 & 6,9 \\
\hline & & Psikologi & 19 & 5,1 \\
\hline & & Peternakan & 13 & 3,5 \\
\hline & & Ilmu Komunikasi & 49 & 13,1 \\
\hline & & Keperawatan & 12 & 3,3 \\
\hline & & $\begin{array}{l}\text { Perikanan dan Ilmu } \\
\text { Kelautan }\end{array}$ & 14 & 3,8 \\
\hline & & $\begin{array}{l}\text { Teknologi Industri } \\
\text { Pertanian }\end{array}$ & 15 & 4 \\
\hline & & Farmasi & 18 & 4,8 \\
\hline & & Teknik Geologi & 16 & 4,3 \\
\hline \multirow[t]{6}{*}{4} & Sivitas akademika & Mahasiswa 2015 & 22 & 5,9 \\
\hline & & Mahasiswa 2016 & 85 & 22,8 \\
\hline & & Mahasiswa 2017 & 49 & 13,1 \\
\hline & & Mahasiswa 2018 & 105 & 28,2 \\
\hline & & Mahasiswa 2019 & 96 & 25,7 \\
\hline & & Tenaga pendidik & 16 & 4,3 \\
\hline
\end{tabular}

Sumber: Hasil pengolahan peneliti, 2020 
